\title{
Isolation and Purification of Secoisolariciresinoldiglucoside oligomers (Lignan) from Flax seed and its evaluation of antioxidant activity
}

\author{
Essam F. Al-Jumaily ${ }^{1}$ and Ahmed H. AL-Azawi ${ }^{1}$

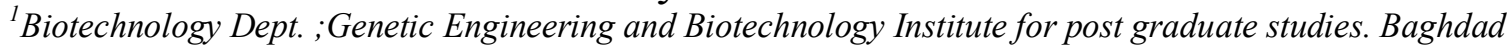 \\ University, Baghdad, Iraq
}

\begin{abstract}
The present study aimed to extract and purify the compound of Secoisolariciresinoldiglucoside oligomers (lignan) from flax seed (Linumusitatissimum) and its antioxidant activity. The Lignan was extracted by solvents which gave the best results were ethanol : 1,4 dioxane $(1: 1, v: v) . S D G$ release after alkaline hydrolysisby using a methanolic $\mathrm{NaOH}, 20 \mathrm{mM}, \mathrm{pH}=8$ at $50{ }^{\circ} \mathrm{C}$. followed by using following chromatographic techniques: Liquid-liquid, Sephadex LH-20 column chromatography, thin layer chromatographic (TLC), high performance liquid chromatographic (HPLC) and Fourier Transform Infra-Red(FTIR). The EC50 values of Pure lignan extract $(9 \mu \mathrm{g} / \mathrm{ml})$ was shown possess DPPH radical scavenging activity compared to reference substances BHT and vitamin $C(E C 50=3$ and $4.2 \mu \mathrm{g} / \mathrm{ml})$ respectively, and this was higher than partial pure lignan component $(E C 50=25.5 \mu \mathrm{g} / \mathrm{ml})$. The total phenolic content of the pure lignanwas higher than partial pure lignan which gave 22.312 and $14.85 \square \mathrm{g} / \mathrm{ml}$ respectively.
\end{abstract}

Key words: Lignan, flax seed, antioxidant activity, Sephadex LH-20, total phenolic

\section{Introduction}

Lignans are diphenolic compounds of higher plants formed by the coupling of two coniferyl alcohol residues that are present in the plant cell wall (Westcott and Muir, 2003). Lignans are a group of polyphenolic compounds in plants that share structural similarities with estrogen and thus have been classified as phytoestrogens. there are two main types of lignans found in flaxseed, secoisolariciresinoldiglycoside and matairesinol, which are contained primarily in the seed coat (Sicilia et al., 2003).

The level of SDG in flaxseed, 1-4\% (w/w) (Eliassonet al., 2003), is 60-700 times higher than that in other edible plant parts (Ford et al., 2001).Variation in flaxseed lignan concentrations depend on the variety, location, and crop year (Westcott and Muir,1996b).Secoisolariciresinol (SECO) amount found in foods. Whole seed and ground flax typically contain between $0.7 \%$ and $1.9 \%$ SDG, which is approximately 77 to $209 \mathrm{mg}$ SDG/tbsp of whole seed or 56 to $152 \mathrm{mg} \mathrm{SDG} / \mathrm{tbsp}$ of ground flaxseed (Morris, 2004).

They lignan are part of large structures such as dimers, trimers, or higher oligomers. The lignans from flaxseeds are linked within an oligomeric structure called the lignan macromolecule (Struijset al. 2007), in which it is covalently bound via ester linkages to 3- hydroxy-3-methyl glutaryl (HMG), A straight chain oligomeric structure composed of 5 SDG residues interconnected by 4 HMGA residues (molecular weight of about 4000 Da)was also reported (Kamal- Eldinet al. 2001).The aims of this study to isolation and purified lignan from flax seed and its evaluationof antioxidant activity.

\section{Materials and Methods}

Flaxseeds were collected from the local market, identified as (Linumusitatissimum L.) by the botanist Prof. Dr. Ali Hussein AL-Musawi in the College of Science / Baghdad University.Firstly, cleaning flax from derbies which include other plants seeds, some parts of vegetarian of flaxseed and dust, Secondly grinding flaxseeds properly by a grinder machine eventually obtained on a homogenized powder that was ready for extraction. This stage involved defatting of flax oils by using Soxhelt apparatus according to (AACC, 1984). Extraction of Crude Lignan by usedthe method which was described by Rickard et al,(1996), involves taking 25 $\mathrm{g}$ of defatted powder treats with a mixture of Dioxan and Ethanol alcohol (1:1),(v:v),respectively, with a ratio (1:8),(w:v),(powder: solvent),sample put on magnetic stir for 4 hrs., then filtrated and the solvent was evaporated by rotary evaporator at $40{ }^{\circ} \mathrm{C}$ to obtained crud lignan.

Separation of Lignan:The process of separation Alkaline hydrolysis of SDG oligomers according to (Li et al. ,2008 and Yuan et al..,2008) by using an alkaline hydrolysis solution (a methanolic $\mathrm{NaOH}, 20 \mathrm{mM}, \mathrm{pH}=8$ ) at $50{ }^{\circ} \mathrm{C}$ for hydrolyzing SDG oligomers. The mixture was filtered by whatman filter paper no. 1 then the supernatant was concentrated with a rotary evaporator within $45^{\circ} \mathrm{C}$. Eventually, a thick sticky texture material ,pH was corrected into 3.0 through adding drops of sulfuric acid 2 molar then the sample was stored in $4{ }^{\circ} \mathrm{C}$. 
This method involves (liquid/ liquid) separation according to Westcott and Muir, (1996a).There were two separating solvent systems which were differed in their polarity these systems include: Ethyl Acetate: distilled water ratio (1:7) using separating funnel. Two layers were formed and take aqueous layer. This process repeated twice and the aqueous layer was concentrated with the rotary evaporator at $45^{\circ} \mathrm{C}$, nearly drying.

SDG extract was separated using Sephadex LH-20 column chromatography (Pharmacia Co.). The column (1.7x $49 \mathrm{~cm}$ )mobilized by add the homogenized gels with ethanol solution concentration $99.9 \%$. The SDG extract was subjected to Sephadex LH-20 column chromatography and eluted with distil water and the flow rate regulated to be $1 \mathrm{~mL} / \mathrm{min}$. Fractions containing SDG were pooled, concentrated to the require volume.

The pure lignan was identified by (HPLC) according to (Westcott and Muir, 1998), using ODS- reverse phase column and an elution system under the following conditions as shown in table (1).

Table (1) Conditions on HPLC of lignan quantification.

\begin{tabular}{|l|l|}
\hline Column & ODS. \\
\hline Column length & $25 \mathrm{~cm}$. \\
\hline Flow rate & $1 \mathrm{ml} / \mathrm{min}$. \\
\hline Wave length & $280 \mathrm{~nm}$ \\
\hline Mobile phase & acetic acid $1 \%$, methanol $30 \%$, water $69 \%$ \\
\hline Retention time & The time is obtained following the experiment. \\
\hline
\end{tabular}

\section{FTIR Assay}

The functional groups in lignan structure were detected to be compared with the standard chart. lignan contains many functional groups: aromatic benzene ring, aromatic hydroxyl groups and the $\mathrm{C}=\mathrm{C}$ double bond but derivatives have more than these functional groups.

In order to obtain an indication of the antioxidant activity of lignan.

Five $\mathrm{mL}$ of a freshly prepared $0.004 \% \mathrm{DPPH}$ solution $4 \mathrm{mg} / 100 \mathrm{~mL}$ in methanol was mixed with 50 $\mu \mathrm{L}$ of different concentration of pure and partial pure lignan $5,10,15,25,35$ and $50 \mathrm{mg} / \mathrm{ml}$ and the absorbance of each dilution, after 30 minutes, was measured at $517 \mathrm{~nm}$. Butylatedhydroxytoluene (BHT) and vitamin $\mathrm{C}$ was the antioxidant used as positive control. (Huang et al, 2005). All tests were performed in triplicate and the methanol was used as blank solution. The percentage DPPH reduction (or DPPH radical scavenging capacity) was calculated as:

$\%$ Reduction $=($ Abs DPPH - Abs Dil. $) /$ Abs DPPH x 100

Whereby:Abs DPPH = average absorption of the DPPH solution

Abs Dil. = average absorption of the three absorption values of each dilution.

With the obtained values, a graphic was made using Microsoft Excel. The $\mathrm{EC}_{50}$ of each extract (concentration of extract or compound at which $50 \%$ of DPPH is reduced) was taken from the graphic.

\section{Determination of total phenolic contents}

The amount of total phenolics in pure and partial pure lignan was determined with the Folin-Ciocalteu reagent. Gallic acid was used as a standard (Figure 1) and the total phenolics were expressed as $\mathrm{mg} / \mathrm{g}$ gallic acid equivalents (Lim et al, 2006) Concentration of 0.005, 0.01, 0.02, 0.03, 0.04 and $0.05 \mathrm{mg} / \mathrm{ml}$ of gallic acid were prepared in methanol.Concentration of 10,25 and $50 \mathrm{mg} / \mathrm{ml}$ of pure and partial lignan were also prepared and $0.5 \mathrm{ml}$ of each sample were introduced into test tubes and mixed with $2.5 \mathrm{ml}$ of a 10 fold dilute Folin- Ciocalteu reagent and $2 \mathrm{ml}$ of $7.5 \%$ sodium carbonate. The absorbance was at read at $760 \mathrm{~nm}$ spectrometrically. All determination was performed in triplicate. Thus total phenolic content can be determin( Savitree et al, 2004 and Pourmorad et al, 2006).

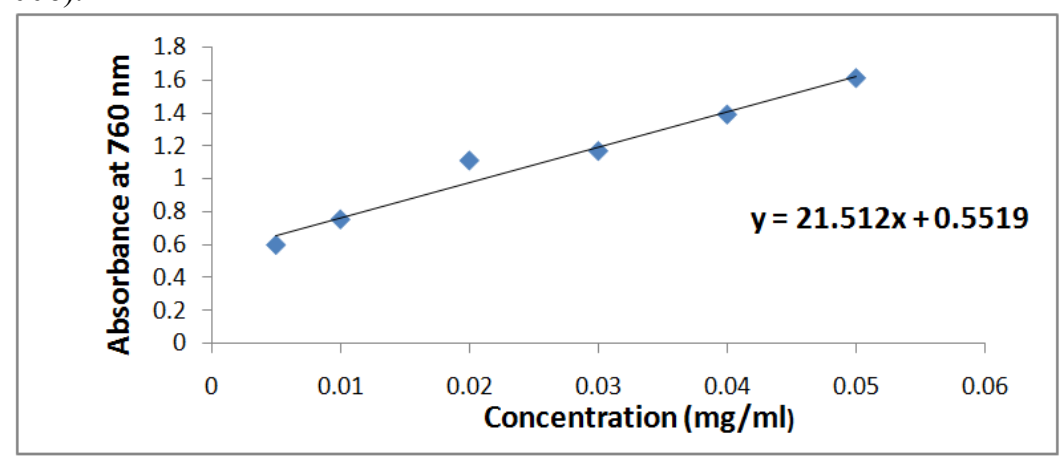

Figure (1): Standard curve of Gallic acid 


\section{Results and Discussion}

The solvents which gave the best results were high purity methanol or $95 \%$ ethanol:1,4dioxane $(1: 1$, $\mathrm{v}: \mathrm{v})$. Westcott and Muir (1996a) patented an alcohol-based method for isolating flaxseed lignan in greater than $90 \%$ purity. The polymeric powder obtained by ethanol :dioxane extraction of defatted flaxseed flour is found to release hydroxy methyl glutaric acid , 4-O- $\beta$-D-glucopyranosylcoumaric acid. (Westcott and Muir, 1996a). Also It had been suggested that p-coumaric acid and ferulic acid glucosides were linked directly via ester linkage of their carboxyl groups to the glucosyl moiety of SDG as a terminal unit in SDG oligomers (Struijset al..2008) and were easily released by alkaline hydrolysis (Johnssonet al.,2002; Ford et al.,2001).

The step followed by extraction is hydrolysis. Alkaline hydrolysis is the main techniques used to prepare samples for chromatographic analysis of lignans (Li et al., 2008). SDG release after alkaline hydrolysis. This step is achieved by two ways:The first way takes a long time to be performed, 48 hours while the second way take a shorter time around 7 hours and it is found that the direct extraction by $\mathrm{NaOH}$ resulted in a higher yield than that obtained by hydrolysis of alcoholic extracts due to the inefficient extraction of oligomers from flaxseed matrix with alcohol. (Yuan et al., 2008).

The addition of $\mathrm{NaOH}$ was necessary to break the ester linkages of SDG oligomers to release SDG, Sodium hydroxide is a base of choice for several inventions (Cui and Han, 2003).

previous study shows that alkaline hydrolysis resulted in the production of methyl esters of $p$-coumaric acid and ferulic acid glucosides, which are stable in methanol; when SDG oligomers were dissolved in water and hydrolyzed by adding an aqueous $\mathrm{NaOH}$ solution, alkaline hydrolysis resulted in the immediate production of $p$-coumaric acid and ferulic acid glucosides; when SDG oligomers were dissolved in aqueous methanol solutions (i.e., $70 \%$ aqueous methanol solution) (Liet al., 2008). Lignan can also be readily obtained from an aqueous ethanol (85\%) extract of flaxseed meal (Empie and Gugger, 2002). Temperatures above room temperature $\left(50\right.$ to $\left.100^{\circ} \mathrm{C}\right)$ are typically used for base hydrolysis. A higher temperature is needed to separate SDG from larger molecular weight compounds such as protein and starch residues which are coagulated and precipitated by the heat (Dobbins and Wiley, 2004). The $\mathrm{pH}$ ranges from 10 to 13 although 11.8 to 12.5 is the preferred range. After hydrolysis, the $\mathrm{pH}$ of the solution needs to be acidified in order to prevent the ionization of any functional groups in the aliphatic and aromatic part of the SDG molecule (Hosseinian and Beta, 2009).

On other hand, primary detection about lignan was carried out with its simplified formula by using thin layer chromatography through two solvent systems (ethyl acetate: ethanol) (1:19), which were prepared for this purpose . The detection in these methods gave the same result characterized by appearing of a dark spot on the silica gel thin layer according to Harbone (1973), where the Rf. value of lignan was 0.45.(Figure 1),this result agree with Al-Jumailyet al., (2012) and Okhti (2005) they found that Rf. value of lignan was 0.45 .

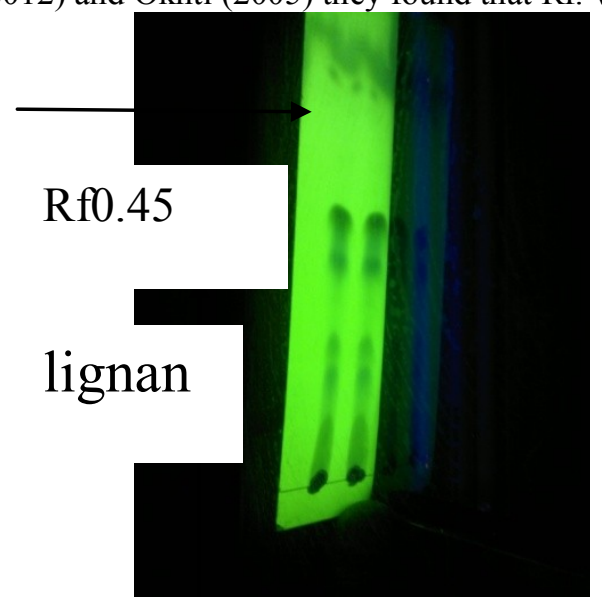

Figure (1):Partition separation of l gnan (partial purification). dark spots and lines of sample loading represent lignan, with Rf. 0.45 .

\section{Separation by Partition (partial purification) liquid/liquid}

Separation of lignan from another compound was carried out by many steps, which include (liq/liq) separation. This process depends on the difference in degree of polarity among compounds which play a key role in the degree of dissolving these structures in two differed solvents in its polarity. Other compounds are considered weaker than lignan (lignan has weak polarity) (Westcott and Muir, 1998). Therefore, lignan dissolves in water while other compounds are dissolving in ethyl acetate when using (ethyl acetate: water).

The end product is a yellow substance not sticky. This is a strong indicator that many unwanted related compounds were removed. The repeated washing increases the purity of lignan, because in the first time both solutions reached were saturated with substances, (AL-Shemary, 2004). 


\section{Purification by column chromatography}

This step is achieved by using ColumnchromatographySephadex LH-20 according to Liet al., (2008) in the purification of lignanfrom the flaxseed. In this study, the purification of SDG was carried out by this Columnchromatography and repeated many times to obtain sufficient amount of lignan.

On the other hand Westcott and Paton,(2001) used another technique called ultrafiltration using solvents systems, separation columns and Millipore filters with different pores size due to the purification depending on molecular weight. In this technique steps of purification were reduced.

When purification of lignanwas done by Colum chromatography, chemical examination was carried out by using chemical reagents. This was specified for sugar groups that are bound by SDG. Structurally, SDG contained two sugar moieties that closely related with SDG. Therefore, these reagents were used to detect these groups, including firstly Molish's reagent. Thus violet color appearance is an indication of SDG. While in Benedict's result, the orange color (which then changed into red sediment in the bottom of test tube) is an indication for SDG. This result is supported by Fehling's reagent where red sediment appeared. This agrees with AL-Awaad (2001) and AL-Shemary (2004), as showed in table (1).

Table (1):Chemical reagents had been used in detection about sugar moieties in SDG compound.

\begin{tabular}{|l|l|l|}
\hline Reagent & Result & Colour \\
\hline Molish's reagent & + & Violet \\
\hline Benedict's reagent & + & Orange \\
\hline Fehling's reagent & + & red sediment \\
\hline
\end{tabular}

\section{Thin Layer Chromatography (TLC)}

Detection about lignan was carried out by using thin layer chromatography through two solvent systems (ethyl acetate: ethanol) (1:19), which were prepared for this purpose .The detection in these methods gave the same result characterized by appearing of a dark spot only on the silica gel thin layer according to Harbone (1973), where the Rf. value of lignan was 0.45. (figure 2).

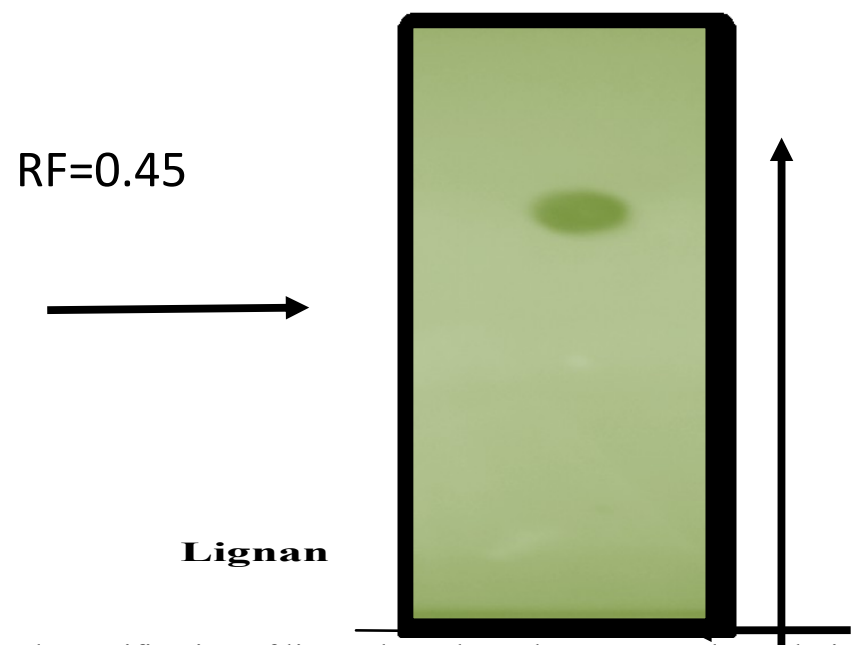

Figure (2): The purification of lignan by colum chromatography technique, Dark line which pointed purified lignan with $\mathrm{Rf}(0.45)$.

\section{High-performance liquid chromatography (HPLC)}

HPLC is the most used analytical technique for detection and quantification of lignan (Willforet al., 2006). HPLC method for analysinglignan in flaxseed was developed by Johnsson et al. (2000) and was later applied by others (Eliassonet al., 2003; Johnssonet al., 2002; Nemes and Orsat, 2010). The SDG submitted to identify by HPLC was purified by the column chromatography on a Sephadex LH-20.

Results of H.P.L.C were revealed that the one peak of SDG and the retention time is $(7.008 \mathrm{~min})$ as shown in figure (3).These results are in line with those of Zhang and Xu, (2007) as shown in figure (4), There is the retention time and one peak that document the SDG as already pure and the percentage of purity is more than $90 \%$. So coloum chromatography is high efficient in purification, similar to those found by (Li et al.,2008).

The isolated SDG was determined by of H.P.L.C (Figure 3) and others tests that were done to detect the purity of SDG. The study also depends on the results of other researches on the same compound like (Westcott and Muir, 1998 and Al-Jumaily et al., 2012) .While Paul and David (1981) used (H.P.L.C and Gel filtration in the purification of lignan) from podophyllum. 


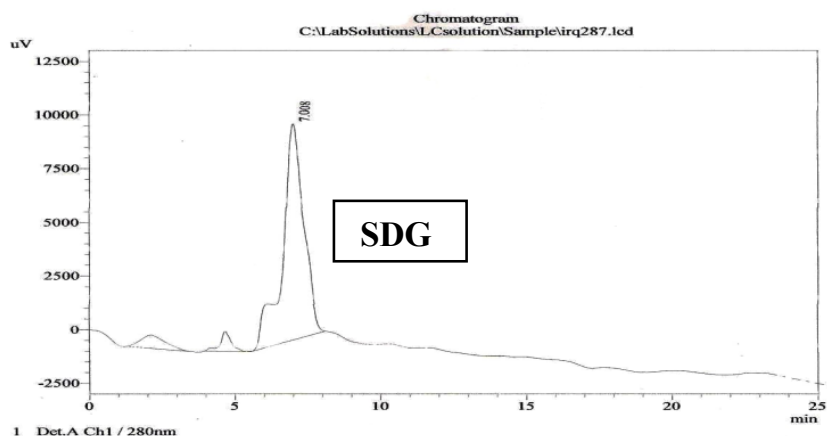

Figure (3): H.P.L.C. quantification of purified lignan SDG, retention time (7.008 min) and the absorbance of lignan .

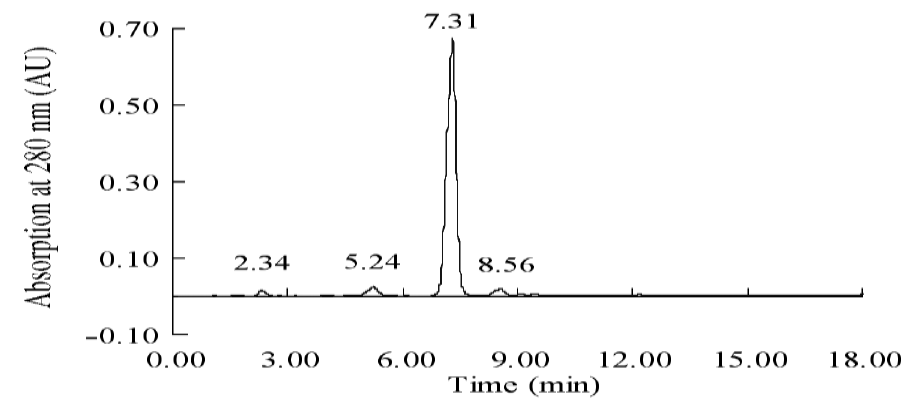

Figure (4): HPLC chromatogram of purified SDG (Zhang and Xu 2007).

\section{Fourier Transform Infra-Red (FTIR) for pure lignan}

Infrared (IR) spectroscopy was applied for the detection and analysis of any purified compound besides the chemical tests. Since I.R light can be reflected from materials, the loading of even small amounts of any product is needed to enhance the very small spectral signal to be recorded (Black and Bale, 2004)

Fourier Transform Infra-Red (FTIR) spectrophotometers were used for recording spectra in the region $4000 \mathrm{~cm}^{-1}$ to $670 \mathrm{~cm}^{-1}(2.5 \mu \mathrm{m}$ to $15 \mu \mathrm{m})$ or in some cases down to $200 \mathrm{~cm}^{-1}(50 \mu \mathrm{m})$. Fourier transform spectrophotometers used polychromatic radiation and calculate the spectrum in the frequency domain from the original data by Fourier transformation (British Pharmacopeia, 2004).Lignan has many functional groups Phenolic- $\mathrm{OH}$ group stretching at wave length 3437.15 , Aromatic $\mathrm{C}=\mathrm{C}$ at wave length 1639.49 and Aliphatic $\mathrm{C}-$ $\mathrm{O}$ at wave length 1103.28 (Table 2). Figure (5) shows the infrared spectra for the extracted pure lignan.

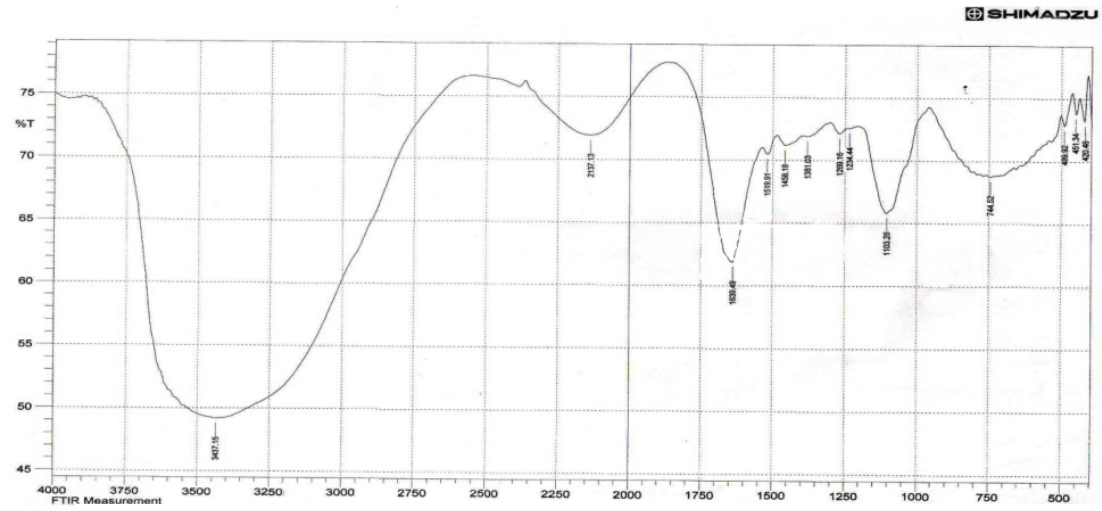

Figure (5): The infrared spectrum for lignan

Table (2): The IR frequencies region for the functional groups of the standard lignan and the extracted pure lignan

\begin{tabular}{|l|l|l||}
\hline The Functional Group & $\begin{array}{l}\text { I.R Frequencies Standard groups }\left(\mathrm{cm}^{-}\right. \\
\text {1) }\end{array}$ & $\begin{array}{l}\text { I.R. Frequencies of Extracted pure } \\
\text { Lignan }\end{array}$ \\
\hline \hline Phenolic-OH group stretching & $3650-2500$ & 3437.15 \\
\hline \hline Aromatic C=C & $1680-1620$ & 1639.49 \\
\hline \hline Aliphatic C-O & $1300-1000$ & 1103.28 \\
\hline
\end{tabular}


The Evaluation Antioxidant activity of lignan was carried out as follows:

Figure (6) illustrates the concentration of DPPH radical due to the scavenging ability of the extract and standards. BHA and vitamin C were used as references. The EC50 values of Pure lignan extract $(9 \mu \mathrm{g} / \mathrm{ml})$ was shown possess DPPH radical scavenging activity compared to reference substances BHT and vitamin C (EC50= 3 and $4.2 \mu \mathrm{g} / \mathrm{ml}$ ) respectively, and this was higher than partial pure lignan component (EC50=25.5 $\mu \mathrm{g} / \mathrm{ml})$.

These findings showed that the flaxseed lignans SDG and SECO exhibited strong antioxidant and protective effects in quenching the DPPH.

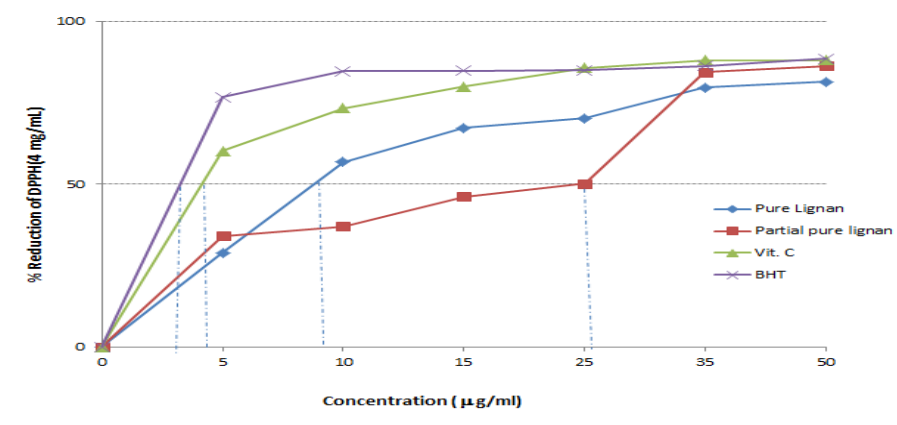

Figure (6): Percentage of DPPH reduction using lignan samples (pure and partial pure) and appropriate controls after 30 min of exposure.

Zanwaret al. (2010) assessed in vitro antioxidant activity of ethanolic extract of L. usitatissimum(EE-LU) by using DPPH radical scavenging, at doses 100, 200, 300, 400 and $500 \mu \mathrm{g} / \mathrm{ml}$. EE-LU showed dose dependant antioxidant activity in different studied models, maximum at $500 \mu \mathrm{g} / \mathrm{ml}$.Kasote, (2013) showedFlaxseed lignans SDG, SECO, ED and EL are found to be equal or somewhat more potent than BHT, vitamin E. Thus, they could have commercial potential as an alternative to these antioxidants. Flaxseed lignans could be the good choice of natural antioxidants for oil stability. Flaxseed antioxidant may have potential application in food and heath industry as food stabilizer, nutraceutical etc.

\section{Determination of total phenolic contents}

Phenolic compounds are a class of antioxidant agents which act as free radical terminators and their bioactivities may be related to their abilities to chelate metals, inhibit lipoxygenase and scavenge free radicals (Roya and Fatemeh, 2013).

The amount of total phenol was determined with the Folin-Ciocalteu reagent. Gallic acid was used as a standard compound and the total phenols were expressed as $\square \mathrm{g} / \mathrm{g}$ gallic acid equivalent using the standard curve equation: $\mathrm{y}=21.512+0.5519$, where $\mathrm{y}$ is absorbance at $760 \mathrm{~nm}$. The total phenolic content of the pure lignanwas higher than partial pure lignan show in (Table 3).

Table (3): Total Phenolic content of pure and partial pure lignan

\begin{tabular}{|l|l|}
\hline Pure lignan $(\mathbf{m g} / \mathbf{m l})$ & Total phenol $(\square \mathbf{g} / \mathbf{g})$ \\
\hline 10 & 12.60 \\
\hline 25 & 18.687 \\
\hline 50 & 22.312 \\
\hline Partial pure lignan (mg/ml) & Total phenol $(\square \mathbf{g} / \mathbf{g})$ \\
\hline 10 & 10.24 \\
\hline 25 & 12.44 \\
\hline 50 & 14.85 \\
\hline
\end{tabular}

The prevailing lignan in the flaxseed is secoisolariciresinoldiglucoside (SDG) (Cardoso Carraroet al., 2012).Plant lignans are the biologically important class of phenolic compounds. They belong to a group of phenols which are characterized by coupling of two phenylpropanoid units (Willforet al., 2006).

The content of SDG varies between 6-29 $\mathrm{g} / \mathrm{kg}$ in the defatted flaxseed powder (Johnssonet al., 2002; Eliassonet al., 2003; Beejmohun, 2007). Flaxseed was reported to contain $8-10 \mathrm{~g} / \mathrm{kg}$ total phenolic acids, about 5 $\mathrm{g} / \mathrm{kg}$ of esterified phenolic acids and 3-5 $\mathrm{g} / \mathrm{kg}$ of etherified phenolic acids (Oomahet al., 1995). They are either in free and/or bound forms. flaxseed possesses about $0.3-0.71 \mathrm{~g}$ of total flavonoids per $\mathrm{kg}$ of flaxseed (Oomahet al., 1996). Flaxseed including minor amounts of phenolic acids as p-coumaric and simple phenols as vanilline (Siger et al., 2008).

SDG is most studied flaxseed phenolic compound pertaining to its in vitro antioxidant potential so far. Flaxseed lignan, SDG exhibited antioxidant activity by either direct radical scavenging or by inhibition of lipid peroxidation. Prasad (1997) studied hydroxyl radical scavenging potential of SDG. The ability of SDG to scavenge exogenously generated hydroxyl radical $(\bullet \mathrm{OH})$ was investigated by using ultraviolet (UV) light photolysis of $\mathrm{H} 2 \mathrm{O} 2$, and by studying ability to prevent $\mathrm{OH}$-induced lipid peroxidation in biological system. 


\section{References}

[1]. Al-Awad, H. A. R. K. (2001). Study the chemical components of Linumusitatissimumthe effect of its extracts on some pathogenic microorganisms. MSc.A thesis, Baghdad University, Ibn AL- Haitham College. (In Arabic)

[2]. Al-Jumaily, E. F.; Al-Shimary, A. O. A. and Shubbr, E. K. (2012). Extraction and Purification of lignan compound from flax seed (Linumusitatissimum) Asian Journal of Plant Science and Research, 2 (3):306-312.

[3]. Al-Shemary, A. O. A. (2004). Extraction and purification of lignan compound from flaxseedLinumusitatissimumand study its antimutagenicity on different systems. MSc.A thesis, Baghdad University, Genetic eng. and Biotech.Inst. (in Arabic).

[4]. American Association of Cereal Chemists (AACC).(1984). Method 08-01. The Association St. Paul, M.N.

[5]. Beejmohun,V. (2007). Coniferindimerisation in lignan biosynthesis in flax cells Phytochemistry, 68: $2744-2752$.

[6]. Black, J.H. and Bale, J.M. (2004). Wilson and Gisvold's textbook of Organic Medicinal and Pharmaceutical Chemistry. Lippincott Willamsand Wilkins. London.

[7]. British pharmacopeia.B.P. 2004.Department of Health and Social Security. Ministry of Health and Social Services for Northernland .published on the recommendation of medicines commission: London Her Majesty stationary office at University Press Cambridge.

[8]. Cardoso carraro, J. C.;Inês de souzadantas, M.; Rocha espeschit, A. C.; Duarte martino, H. S. and Rocha ribeiro, S. M. (2012). Flaxseed and Human Health: Reviewing Benefits and Adverse Effects. Food Reviews International 28: 203 -230.

[9]. Cui, W. and Han, N. F. (2003).Process and apparatus for flaxseed component separation.U.S Patent Application 0030136276.

[10]. Eliasson, C.; Kamal-Eldin, A.; Andersson, R. and Aman, P. (2003) .High performance liquid chromatographic analysis of secoisolariciresinoldiglucoside and hydroxycinnamic acid glucosides in flaxseed by alkaline extraction. J. Chromatogr. A, 1012: 151159.

[11]. Empie, M. and Gugger, E. (2002).Method of preparing and using isoflavones for the treatment of neurological symptoms. US patent $6: 310$.

[12]. Ford, J. D.; Huang, K. S.; Wang, H. B.; Davin, L. B. and Lewis, N. G. (2001). Biosynthetic pathway to cancer chemopreventivesecoisolariciresinoldiglucoside-hydroxymethylglutaryl ester-linked lignan oligomers in flax (Linumusitatissimum) seed. Journal of Natural Products 64: 1388-1397.

[13]. Harbone, J. B. (1973). Phytochemical methods. Aguide to modern techniques of plant analysis.Chapman and hall, London.

[14]. Hosseinian, F. S. and Beta, T. (2009).Patented Techniques for the Extraction and Isolation of SecoisolariciresinolDiglucoside from Flaxseed. Recent Patents on Food, Nutrition \& Agriculture, 1: 25-31.

[15]. Huang, D.; Ou, B. and Prior, R. L. (2005). The chemistry behind antioxidant capacity assays. Journal of Agricultural and Food Chemistry, 53: 1841-1856.

[16]. Johnsson, P.; Peerlkamp, N.; Kamal-Eldin, A.; Andersson, R. E.; ersson, R.; Lundgren, L. N. and Åman, P. (2002). Polymeric fractions containing phenol glucosides in flaxseed. Food Chem., 76: 207-212.

[17]. Kasote, D. M. (2013).Flaxseed phenolics as natural antioxidants. International Food Research Journal $20(1): 27-34$.

[18]. Kamal-Eldin, A.; Peerlkamp, N.; Johnsson, P.; Andersson, R.; Andersson, R. E.; Lundgren, L. N. and Åman, P. (2001). An oligomer from flaxseed composed of secoisolariciresinoldiglucoside and 3-hydroxy-3-methyl glutaric acid residues. Phytochemistry58 (4): 587-590.

[19]. Li, X.; Yuan, J. P.; Xu, S. P.; Wang, J. H. and Liu, X. (2008). Separation and determination of secoisolariciresinoldiglucoside oligomers and their hydrolysates in the flaxseed extract by high-performance liquid chromatography. Journal of Chromatography A, 1185: 223-232.

[20]. Nemes, S. M. and Orsat, V. (2011).Microwave-assistedextraction of secoisolariciresinoldiglucoside.Methoddevelopment.Food Bioprocess. Technol., 4: 1219-1227.

[21]. Lim, Y. Y.; Lim, T. T. and Jing, J. (2006). Antioxidant Properties of Guava Fruit: Comparison With Some Local Fruits, Sunway Academic Journal 3: 9-20

[22]. Morris, D. H. (2004).Flax-A Health and Nutrition Primer. Nutrition. 18:44-50.

[23]. Pourmorad, F.; Hosseinimehr, S. J. and Shahabimajd, N. (2006).Antioxidant activity, phenol and flavonoid contents of some selected Iranian medicinal plants, African Journal of Biotechnology Vol.5 (11) 1142-1145.

[24]. Okhti, Z. (2005). Study The Effect of Lignan Isolated From Flaxseed on Hypercholesteremia and Acetylcholinesterase Activity on Rabbit. MS.c.A thesis, Baghdad University, Genetic eng. and Biotech.Inst.

[25]. Oomah, B. D.;Kenaschuk, E. O. and Mazza, G. (1995).Phenolic acids in flaxseed. Journal of Agriculture and Food Chemistry 43: 2016-2019.

[26]. Oomah, B. D.;Mazza, G. and Kenaschuk, E. O. (1996).Flavonoid content of the flaxseed, influence of cultivar and environment.Euphytica 90: 163-167.

[27]. Prasad, K. (1997). Hydroxyl radical-scavenging property of secoisolariciresinoldiglucoside (SDG) isolated from flax-seed. Mol Cell Biochem. 168: 117-23.

[28]. Rickard, S. E.; Orcheson, L. J.; Seidl, M. M.; Luyengi, L.; Fong, H. H. S. and Thompson, L. U. (1996). Dose dependent production of mammalian ignans in rats and in vitro from the purified precursor secoisolariciresinoldiglycoside in flaxseed. J. Nutr. 126: 20I22019.

[29]. Roya, K. and Fatemeh, G. (2013).Screening of total phenol and flavonoid content, antioxidant and antibacterial activities of the methanolic extracts of three Silene species from Iran.Intl. J. Agri. Crop Sci. 5 (3): 305-312.

[30]. Sicilia, T.; Niemeyer, H. B.;Honig, D. M. and Metzler, M. (2003). Identification and stereochemical characterization of lignans in flaxseed and pumpkin seeds.Journal of Agricultural and Food Chemistry, 51: 1181-1188.

[31]. Siger, A.; Nogala-Kalucka, M. and Lampart-Szczapa, E. (2008). The content and antioxidant activity of phenolic compounds in coldpressed plant oils. J. Food Lipids. 15: 137-149.

[32]. Struijs, K.; Vincken, J. P.; Verhoef, R.; Oostveen-van Casteren, W. H. M.; Voragen, A. G. J. and Gruppen, H. (2007). The flavonoid herbacetindiglucoside as a constituent of the lignan macromolecule from flaxseed hulls. Phytochemistry68: 1227-1235.

[33]. Struijs, K.; Vincken, J. P.; Verhoef, R.; Voragen, A. G. J. and Gruppen, H. (2008).Hydroxycinnamic acids are ester-linked directly to glucosyl moieties within the lignan macromolecule from flaxseed hulls. Phytochemistry, 69: 1250-1260.

[34]. Westcott, N. D. and Muir, A. D. (1996a). Process for extracting and purifying lignans and cinnamic acid derivatives from flax seed. PCT patent WO9630468A2.

[35]. Westcott, N. D. and Muir, A. D. (1996b). Variation in the concentration of the flax seed lignan concentration with variety, location and year.Proceedings of the 56th Flax Institute of the United States.pp 77-80. Flax Institute of the United States, Fargo, ND.

[36]. Westcott, N. D. and Muir, A. D. (1998).Process for extracting lignan from flaxseed US Patent; US 005705618.

[37]. Westcott, N. D. and Paton, D. (2001).A complex containing lignan, phenolic and aliphatic substances from flax and process for preparing. U.S. Patent 6: 264. 
[38]. Willfor, S. M.;Smeds, A. I. and Holmbom, B. R. (2006).Chromatographic analysis of lignans (review). Journal of Chromatography A 1112: 64-77.

[39]. Yuan, J. P.; Li, X.;Xu, S. P.; Wang, J. H. and Liu, X. (2008).Hydrolysis Kinetics of SecoisolariciresinolDiglucoside Oligomers from Flaxseed.J. Agric. Food Chem., 56 (21): 10041-10047.

[40]. Zanwar, A. A.;Hegde, M. V. and Bodhankar, S. L. (2010).In vitro antioxidant activity of ethanolic extract of Linumusitatissimum. Pharmacologyonline 1: 683-696.

[41]. Zhang, W. and Xu, S. (2007).Purification of SecoisolariciresinolDiglucoside with Column Chromatography on a Sephadex LH20.Journal of Chromatographic Science, Vol. 45 